\title{
Detection of Nitrite by Copper Interdigitated Electrode with Nickel-Cobalt Nanowires
}

\author{
Yaw-Jen Chang* Guo-Hao Shen Shun-Yang Liu \\ Department of Mechanical Engineering \\ Chung Yuan Christian University \\ Chung Li District, Taoyuan City, Taiwan \\ justin@cycu.edu.tw
}

\begin{abstract}
This paper presents an analytic chip consisting of copper interdigitated electrodes ( $\mathrm{Cu}$-IDE) and nickel-cobalt alloy nanowires (Ni-Co NWs) for the measurement of nitrite. Surface modification using 5-amino-1,3,4-thiadiazole-2-thio (ATT) was performed to promote the binding ability of $\mathrm{Ni}-\mathrm{Co} \mathrm{NWs}$ with nitrite ions. Then, electrical measurement using HP 4145B semiconductor parameter analyzer was carried out for detecting the nitrite concentrations. The experimental results show that the measured curves of nitrite concentrations are distinguishable and in concentration order. The detection limit was $0.04 \mathrm{mM}$. However, only $2 \mu \mathrm{L}$ of nitrite solution was required for measurement.
\end{abstract}

Keywords-nitrite, interdigitated electrode, 5-amino-1,3,4thiadiazole-2-thio (ATT)

\section{INTRODUCTION}

In recent years, food safety scandals have erupted again and again in many countries. Many kinds of foods have been found to be tainted with banned substances for making the ingredient look nicer or preserve longer. These substances might be harmful to human health and lead to environmental pollution. Hence, food safety problems usually cause public anxiety and, furthermore, destroy the public trust in the government.

Nitrites, usually serving as preservatives, are widely used because they prevent bacterial growth and give the food products a desirable pink-red "fresh" color. For instance, pickled foods are typically preserved using nitrite ions. Unfortunately, nitrite is known to be relatively toxic. Ingestion of high concentration of nitrite from foods is not allowed because nitrite can react with secondary amines to form nitrosamines, which are known to cause stomach and bowel cancers or other kinds of tumors. Moreover, nitrite promotes the irreversible oxidization of hemoglobin to methemoglobin so that it reduces the blood capacity to transport oxygen and results in health risks. Therefore, the quantification of nitrite existing in food, drinking water and environmental samples is of great importance.

There are several conventional approaches for nitrite determination, such as spectrometric detection [1-3], chromatographic method [4-6], and capillary electro-phoresis [7-9]. Moreover, electrochemical approaches, e.g. cyclic voltammetry [10-12], are also widely used to measure nitrite

This work was supported by the Ministry of Science and Technology (MOST) of Taiwan, R.O.C. (MOST 106-2221-E-033-069) ions. Electrochemical methods have advantages of easy operation and fast response. By means of oxidation or reduction at the working electrode, this electrochemical reaction results in an electric current that passes through the external circuit. Hence, electrode is the essential element for electrochemical measurement.

Over the past few years, interdigitated electrode (IDE) is a widely used structure as sensing component due to its promising feature in sensing applications. Alternatively, nanowires (NWs) are also thought of as ideal elements for sensing devices. The research of nanowires has grown tremendously and implemented to different fields such as biological and chemical processes. Therefore, sensors incorporating IDEs with nanowires are expected to enhance the analytical performance and robustness.

There are various approaches to synthesize nanowires. Hydrothermal synthesis is a simple and popular method $[13,14]$. Vapor-liquid-solid (VLS) process is a common technique able to create crystalline nanowires of some semiconductor materials [15-17]. Template synthesis is another method to produce nanowires by electrodeposition with the help of porous templates $[18,19]$. In this study, we demonstrate a method that incorporates IDE with template-synthesized nanowires to measure small quantity of nitrite.

\section{MATERIALS AND METHODS}

\section{A. Materials}

Sodium nitrite (extra pure reagent) was used for experiments. In addition, 5-amino-1,3,4-thiadiazole-2-thiol $\left(=\mathrm{C}_{2} \mathrm{H}_{3} \mathrm{~N}_{3} \mathrm{~S}_{2}\right.$, ATT $)$ was used to capture nitrite. When ATT dissolves in water, the decomposed $\mathrm{H}_{3} \mathrm{~N}_{3} \mathrm{~S}_{2}$ can bind with nitrite ion, as shown schematically in Fig. 1. Phosphate buffered saline (PBS) was used to prepare ATT solution.

Anodic alumina oxide membrane (AAO) with cylindrical pores of $200 \mathrm{~nm}$ in diameter was purchased from Whatman Inc. (USA). The necessary chemicals for $\mathrm{Ni}-\mathrm{Co}$ electrodeposition included $\mathrm{Ni}\left(\mathrm{NH}_{2} \mathrm{SO}_{3}\right)_{2} \cdot 4 \mathrm{H}_{2} \mathrm{O}$, $\mathrm{Co}\left(\mathrm{NH}_{2} \mathrm{SO}_{3}\right)_{2} \cdot 4 \mathrm{H}_{2} \mathrm{O}, \quad \mathrm{NiCl}_{2} \cdot 6 \mathrm{H}_{2} \mathrm{O}, \quad \mathrm{H}_{3} \mathrm{BO}_{3}, \quad \mathrm{NiCO}_{3}$, and $\mathrm{HSO}_{3} \mathrm{HN}_{2}$, among which $\left(\mathrm{NH}_{2} \mathrm{SO}_{3}\right)_{2} \cdot 4 \mathrm{H}_{2} \mathrm{O}$ and $\mathrm{NiCO}_{3}$ were used to adjust the $\mathrm{pH}$ of the plating bath to 4.1. Additionally, a low-stress additive (sodium saccharin, $\mathrm{C}_{6} \mathrm{H}_{4} \mathrm{SO}_{2} \mathrm{NNaCO} \cdot 2 \mathrm{H}_{2} \mathrm{O}$ ) was used. It is a surfactant to assist the progress of 
electroplating. All these materials were purchased from Blue Giant Inc. (Taiwan).

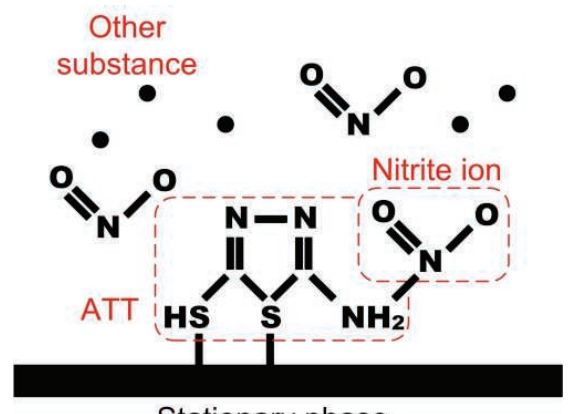

Stationary phase

Fig. 1. Functional group of ATT captures nitrite ions on the substrate surface.

\section{B. Fabrication Process}

The chip for nitrite detection consists of an interdigitated electrode and $\mathrm{Ni}-\mathrm{Co}$ nanowires lying on the fingers of IDE. The printed circuit board (PCB) was adopted for the fabrication of the interdigitated electrode. The copper foil of PCB was etched using the conventional PCB treatment to form the $\mathrm{Cu}$ IDE which was characterized by 3 interdigitated fingers, with finger width of $150 \mu \mathrm{m}$, length of $5.1 \mathrm{~mm}$, and gap of $350 \mu \mathrm{m}$, as shown in Fig. 2. In order to constrain the experimental area on $\mathrm{Cu}-\mathrm{IDE}$, a layer of polydimethylsiloxane (PDMS) with a hole opened at the region of fingers of IDE was bond onto the PCB substrate. We opened the round hole in the PDMS layer using a hole punch, which is a kind of craft tool.

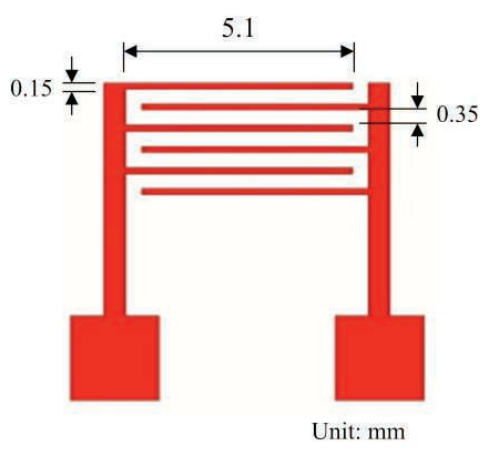

Fig. 2. The design of the interdigitated electrode.

$\mathrm{Ni}-\mathrm{Co}$ nanowires were synthesized by electro-deposition method using a porous AAO as template for nanowire growth. AAO was first coated with an alumina film using a thermal evaporator system in its branched side to serve as cathode during the electrodeposition. Then, Ni-Co electrodeposition was performed in a W18 cm $\times$ L25 cm $\times$ H18 cm electroplating tank. A $100 \mathrm{~V} / 5 \mathrm{~W}$ pump equipped at the bottom of the tank provided a flow upward to the metal substrate in order to enhance the turbulence for promoting uniformity of the plating bath. To eliminate impurities and crystalline solids, a filter with $1 \mu \mathrm{m}$ pores was installed above the pump. Furthermore, a digital power supply controlled by a PID controller supplied a $100 \mathrm{~V} / 100 \mathrm{~W}$ output to a quartz heater for temperature control of the plating bath at $45^{\circ} \mathrm{C}$. The fabrication process of Ni-Co NWs is shown in Fig. 3.

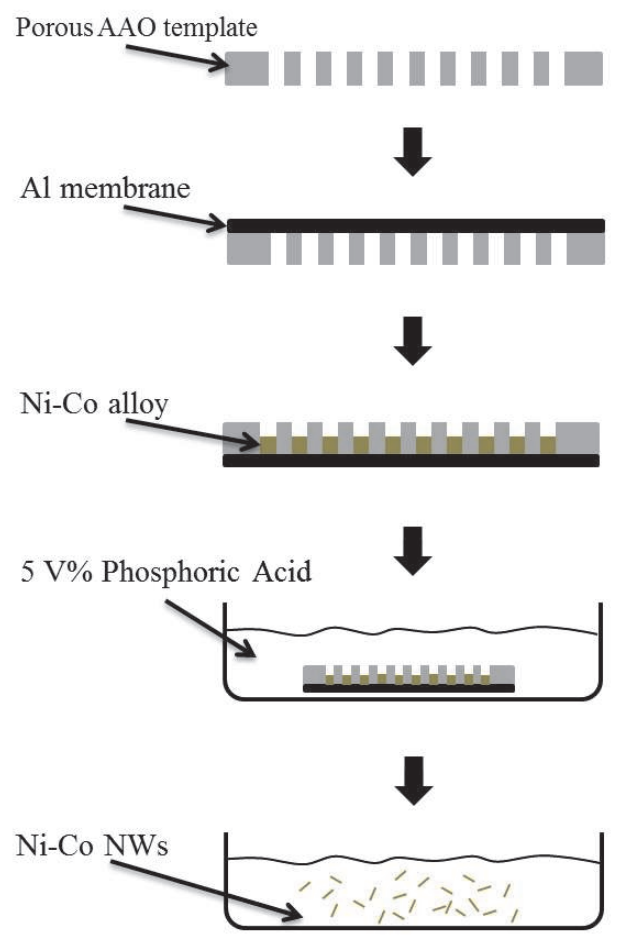

Fig. 3. Fabrication process of $\mathrm{Ni}-\mathrm{Co}$ nanowires.

In order to release the $\mathrm{Ni}-\mathrm{Co} \mathrm{NWs}$ from the AAO template, a chemical etching procedure was carried out. The alumina membrane was dissolved by immersion in phosphoric acid solution $(5 \mathrm{~V} \%)$ at $45^{\circ} \mathrm{C}$ for $2 \mathrm{~h}$. Once in suspension, the $\mathrm{Ni}-\mathrm{Co}$ NWs were gathered by a magnet and, sequentially, transferred to a microcentrifuge tube where NWs were dispersed in methanol.

\section{Experiment}

To prepare ATT solution, the $\mathrm{C}_{2} \mathrm{H}_{3} \mathrm{~N}_{3} \mathrm{~S}_{2}$ powder was thoroughly dissolved in PBS with the assistance of ultrasonicator. In addition, $2 \mu \mathrm{L}$ of methanol containing Ni-Co NWs was drawn from the microcentrifuge tube and introduced onto the fingers of IDE, followed by dehydration baking in a $60^{\circ} \mathrm{C}$ oven. Then, ATT solution was injected atop the Ni-Co NWs. The chip was remained stationary for $40 \mathrm{~min}$ to allow the surface of Ni-Co NWs being modified with ATT.

Three groups of experiments were carried out in this study. Cyclic voltammetry (CV), which is a type of potentiodynamic electrochemical measurement, was employed to study the redox potentials of $\mathrm{Ni}-\mathrm{Co}$ film and ATT in the first group of experiment. In the second group of experiment, different types of chips were compared: (1) ATT modified IDE; (2) NW-IDE without ATT modification; (3) ATT modified NW-IDE. Finally, the detection limit was investigated in the third group of experiment. 


\section{RESULTS AND DISCUSSION}

\section{A. Cyclic Voltammetry}

A chip with ATT modified Ni-Co film (area: $1 \mathrm{~cm}^{2}$ ) was adopted for the cyclic voltammetry experiment. The working electrode potential was ramped linearly from $0 \mathrm{~V}$ to $0.5 \mathrm{~V}$ versus time. The scan rate, i.e. the rate of voltage change over time, was $0.01 \mathrm{~V} / \mathrm{s}$. During the initial forward scan, the potential from $0 \mathrm{~V}$ to $0.5 \mathrm{~V}$ was applied and, in the meantime, the oxidation reaction occurred. The potential from $0.55 \mathrm{~V}$ to 0 $\mathrm{V}$ was subsequently applied and the reduction reaction occurred. The reactions are formulated as below. In addition, the cyclic voltammogram trace, i.e. the current at the working electrode versus the applied voltage, is shown in Fig. 4.

Oxidation:

$$
\mathrm{NO}_{2}^{-} \rightarrow \mathrm{NO}_{2}+e^{-}
$$

The nitrite ion loses its ion and, thus, is captured by the functional group of ATT. The current reaching a peak, called oxidation peak, at the applied voltage of $0.39 \mathrm{~V}$ explains that at this moment the most concentration of nitrite is educed.

Reduction:

$$
\mathrm{NO}_{2}+e^{-} \rightarrow \mathrm{NO}_{2}^{-}
$$

On the contrary, the nitrite gains an ion to restore the form of nitrite ion. However, the reduction peak is not obvious because Ni-Co alloy might affect the reaction.

Since the complete cyclic voltammogram could not be obtained, the measurement was then performed using HP 4145B semiconductor parameter analyzer. Information about an analyte is obtained by measuring the current as the potential is varied.

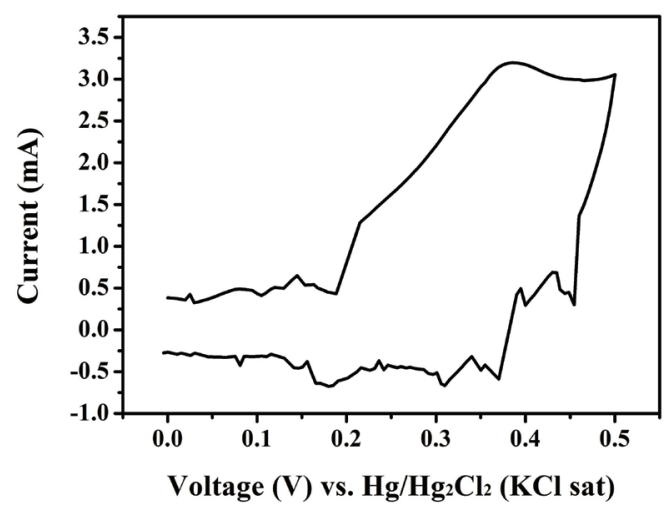

Fig. 4. Cyclic voltammogram of nitrite solution using a chip with ATT modified Ni-Co film.

\section{B. Surface Modification of ATT}

To examine the effect of surface modification of ATT, two different types of chips were compared: (1) NW-IDE without ATT modification; (2) ATT modified NW-IDE. Prior to the experiments, measurement of deionised (D.I.) water was carried out using a NW-IDE without ATT modification. This result was treated as the baseline. Hence, all successive measurements of nitrite ions can be compared with this baseline. For each type of chip, a droplet of $2 \mu \mathrm{L}$ nitrite solution (concentration: $0.2 \mathrm{mM}$ ) was injected onto the chip, followed by voltammetry measurement. Figure 5 shows the results.

For NW-IDE without ATT modification, the curve of measurement almost overlaps with the baseline. This result reveals that the nitrite ions cannot be captured for measurement without the surface modification of ATT. On the other hand, the discrimination between the measurement curve of ATT modified NW-IDE and the baseline is obvious. Hence, the effect of ATT to capture nitrite ions is confirmed.

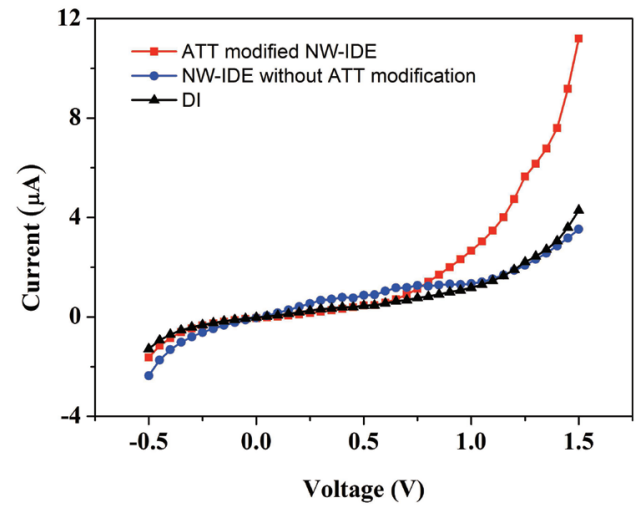

Fig. 5. The effect of surface modification of ATT.

\section{Measurement of Different Concentrations}

Next, the subsequent experiments focused on the investigation of ATT modified NW-IDE to detect different concentrations of nitrite solutions. Three different concentrations of nitrite solutions were designed for comparison: $0.05 \mathrm{mM}, 0.1 \mathrm{mM}$, and $0.2 \mathrm{mM}$.

As shown in Fig. 6, the measured curve of $0.05 \mathrm{mM}$ nitrite solution is close to the baseline. However, these four curves are distinguishable. This result explains that ATT modified NWIDE is able to measure different concentrations of nitrite solutions. Especially, for higher concentration (e.g. $0.2 \mathrm{mM}$ ) of nitrite solution, the curve rises up parabolically.

\section{Detection Limit}

To examine the minimal concentration that the ATT modified NW-IDE can detect, the nitrite solutions were prepared in a series of concentration gradients from $0.05 \mathrm{mM}$ to $0.02 \mathrm{mM}$. If the measurement curve overlaps with the baseline, it reaches the detection limit at which this sensor cannot distinguish the nitrite solution from the deionized water.

As shown in Fig. 7, the detection limit is $0.04 \mathrm{mM}$. That is, a valid measurement can be conducted using this ATT modified NW-IDE if the concentration of nitrite solution is greater than $0.04 \mathrm{mM}$. Otherwise, the measurement curve overlaps with the baseline and becomes undistinguishable. 


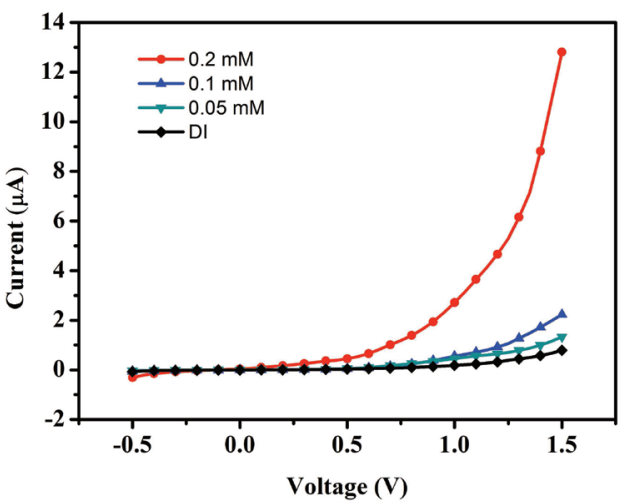

Fig. 6. Measurement of different concentrations of nitrite solutions using ATT modified NW-IDE.

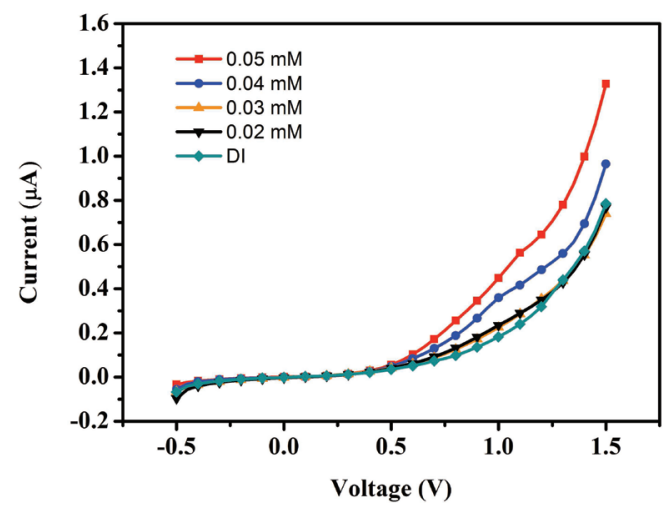

Fig. 7. Detection limit of ATT modified NW-IDE.

\section{CONCLUSIONS}

This proposed ATT modified NW-IDE sensor is able to detect the nitrite concentrations with the measured curves distinguishable and in concentration order. The detection limit was $0.04 \mathrm{mM}$. Although this sensor cannot detect very low concentration of nitrite solution, it has an advantage that the measurement can be conducted in a smaller consumption volume of specimen. Only $2 \mu \mathrm{L}$ of nitrite solution is required for measurement so that this sensor has potential implementations to food monitoring. To improve the sensitivity of this sensor, the method of surface modification is surely a hinge. Finding another substance to bind with the nanowires as well as to capture the nitrite ions is an important issue in the future.

\section{REFERENCES}

[1] G. F. Wang, M. Satake, and K. Horita, "Spectrophotometric determination of nitrate and nitrite in water and some fruit samples using column preconcentration," Talanta, vol. 46, pp. 671-678, 1998.
[2] A. Kazemzadeh and A. A. Ensafi, "Sequential flow injection spectrophotometric determination of nitrite and nitrate in various samples," Analytica Chimica Acta, vol. 442, pp. 319-326, 2001.

[3] N. Beda and A. Nedospasov, "A spectrophotometric assay for nitrate in an excess of nitrite," Nitric Oxide-Biol. Chem., vol. 13, pp. 93-97, 2005.

[4] E. N. Kapinus, I. A. Revelsky, V. O. Ulogov, and Y. A. Lyalikov, "Simultaneous determination of fluoride, chloride, nitrite, bromide, nitrate, phosphate and sulfate in aqueous solutions at $10^{-9}$ to $10^{-8} \%$ level by ion chromatography," J. Chromatogr. B, vol. 800, pp. 321-323, 2004.

[5] R. Tachon, V. Pichon, M. B. Le Borgne, and J. J. Minet, "Use of porous graphitic carbon for the analysis of nitrate ester, nitramine and nitroaromatic explosives and by-products by liquid chromatographyatmospheric pressure chemical ionisation-mass spectrometry," J. Chromatogr. A, vol. 1154, pp. 174-181, 2007.

[6] C. Lopez-Moreno, I. V. Perez, and A. M. Urbano, "Development and validation of an ionic chromatography method for the determination of nitrate, nitrite and chloride in meat," Food Chem., vol. 194, pp. 687-694, 2016.

[7] P. A. Marshall and V. C. Trenerry, "The determination of nitrite and nitrate in foods by capillary ion electrophoresis," Food Chem., vol. 57, pp. 339-345, 1996.

[8] F. Della Betta, L. Vitali, R. Fett, and A. C. Costa, "Development and validation of a sub-minute capillary zone electrophoresis method for determination of nitrate and nitrite in baby foods," Talanta, vol. 122, pp. 23-29, 2014.

[9] P. Tuma, "The use of polarity switching for the sensitive determination of nitrate in human cerebrospinal fluid by capillary electrophoresis with contactless conductivity detection," J. Chromatogr. A, vol. 1447, pp. $148-154,2016$.

[10] J. J. Feng, P. P. Zhang, A. J. Wang, Y. Zhang, W. J. Dong, and J. R. Chen, "One-pot hydrothermal synthesis of uniform $\beta-\mathrm{MnO}_{2}$ nanorods for nitrite sensing," J. Colloid Interface Sci., vol. 359, pp. 1-8, 2011.

[11] Y. Zhang, R. Yuan, Y. Chai, X. Zhong, and H. Zhong, "Amperometric sensor for nitrite using a glassy carbon electrode modified with thionine functionalized MWCNTs/Au nanorods/SDS nanohybrids," Surf. Interface Anal., vol. 44, pp. 1233-1237, 2012.

[12] K. Rajalakshmi and S. A. John, "Highly sensitive determination of nitrite using FMWCNTs-conducting polymer composite modified electrode," Sens. Actuators B- Chem., vol. 215, pp. 119-124, 2015.

[13] J. Song and S. Lim, "Effect of seed layer on the growth of $\mathrm{ZnO}$ nanorods," J. Phys. Chem. C, vol. 111, pp. 596-600, 2007.

[14] J. Song, S. Baek, J. Lee, and S. Lim, "Role of $\mathrm{OH}^{-}$in the low temperature hydrothermal synthesis of $\mathrm{ZnO}$ nanorods," Chem. Technol. Biotechnol., vol. 83, pp. 345-350, 2008.

[15] W. Y. Weng, T. J. Hsueh, S.-J. Chang, G. J. Huang, and S. C. Hung, "Growth of $\mathrm{Ga}_{2} \mathrm{O}_{3}$ nanowires and the fabrication of solar-blind photodetector," IEEE Trans. Nanotechnol., vol. 10, pp. 1047-1052, 2011.

[16] I. Castro-Hurtado, J. Herrán, G. Ga Mandayo, and E. Castaño, " $\mathrm{SnO}_{2}$ nanowires grown by catalytic oxidation of tin sputtered thin films for formaldehyde detection," Thin Solid Films, vol. 520, pp. 4792-4796, 2012.

[17] V. Consonni, E. Sarigiannidou, E. Appert, A. Bocheux, S. Guillemin, F. Donatini, I.-C. Robin, J. Kioseoglou, and F. Robaut, "Selective area growth of well-ordered $\mathrm{ZnO}$ nanowire arrays with controllable polarity," ACS Nano, vol. 8, pp. 4761-4770, 2014.

[18] V. A. Antohe, A. Radu, M. Mátéfi-Tempfli, A. Attout, S. Yunus, P. Bertrand, C. A. Duţu, A. Vlad, S. Melinte, S. Mátéfi-Tempfli, et al., "Nanowire-templated microelectrodes for high-sensitivity $\mathrm{pH}$ detection," Appl. Phys. Lett., vol. 94, 073118, 2009.

[19] X. Li, E. Chin, H. Sun, P. Kurup, and Z. Gu, "Fabrication and integration of metal oxide nanowire sensors using dielectrophoretic assembly and improved post-assembly processing," Sens. Actuator BChem., vol. 148, pp. 404-412, 2010. 